\title{
Leadership and conservation effectiveness: finding a better way to lead
}

\author{
Simon A. Black ${ }^{1}$, Jim J. Groombridge ${ }^{1}$, \& Carl G. Jones ${ }^{2,3}$ \\ ${ }^{1}$ Durrell Institute of Conservation and Ecology, University of Kent, Canterbury, Kent, UK \\ ${ }^{2}$ Durrell Wildlife Conservation Trust, Trinity, Jersey, Channel Islands \\ ${ }^{3}$ Mauritian Wildlife Foundation, Grannum Road, Vacoas, Mauritius
}

Keywords
Adaptive management; effectiveness;
governance; management; species
conservation; systems
Correspondence
Dr Simon Black, Durrell Institute of Conservation
and Ecology, Marlowe Building, University of
Kent, Canterbury, Kent, CT2 7NR UK. Tel: +44
(0) 1227 823667; Fax: +44 (0) 1227827289.
E-mail: S.Black@kent.ac.uk
Received
11 December 2010
Accepted
2 April 2011
Editor
Bill Adams
doi: $10.1111 / j .1755-263 \times .2011 .00184 . x$

Keywords

conservation; systems

and Ecology, Marlowe Building, University of

Kent, Canterbury, Kent, CT2 7NR UK. Tel: +44

823667: Fax: +44 (0) 1227827289

Received

11 December 2010

Accepted

Editor

doi: 10.1111/j.1755-263X.2011.00184.X

\begin{abstract}
Conservation practitioners and academics have highlighted leadership as an important component for conservation programs, but the attributes of effective leaders are not yet clearly defined. We identify a leadership approach that enables a conservation organization to be more effective in achieving positive results. An analysis of successful and unsuccessful species conservation programs consistently reveals contrasting leadership approaches. Successful approaches resonate strongly with both the characteristics of species conservation and established leadership theory in mainstream management literature. We describe the practices identified in successful species conservation programs to provide the basis for a new understanding of conservation leadership using established management theory. The traits of a successful conservation leader include: an ability to share a clear, long-term vision; orientation toward "hands-on" management; an ability to switch thinking between the big picture and the detail; and a willingness to encourage learning, improvement, and receptiveness to alternative solutions. Activities in the conservation sector are typically influenced by factors beyond the control of managers. Conversely, a leadership approach is under managers' direct control and has an impact on attainment of results. Effective leadership is one factor that should not be left to chance but should be considered seriously for its impact on achievement in biodiversity conservation.
\end{abstract}

\section{Introduction}

During the last three decades, growth in the number of species conservation projects has generated considerable interest in how they are managed, and why some programs succeed while others fail (Balmford \& Cowling 2006; Manolis et al. 2009). With the development of the current global community of government agencies and multinational nongovernment organizations (NGOs), leadership has received renewed consideration (Manolis et al. 2009; Sutherland et al. 2009) and has been described as "the most important attribute in the toolkit of a conservation biologist" (Deitz et al. 2004). A review of management structures, culture, and politics in contemporary species conservation projects reveals contrasts in modes of operation, leadership phi- losophy, and achievement (Clark et al. 1994). We consider species conservation programs, examine leadership in the context of modern conservation biology, and explore the impact of leadership on conservation success. Species programs enable ready comparison due to their relatively simple goals and management process. Nevertheless, the approaches presented here have been effective in many sectors (e.g., manufacturing, services, military, health, public sector) for diverse organizations with differing stakeholders (Womack \& Jones, 1996; Seddon 2003; Kim et al. 2006; Reed 2006), so the leadership principles we identify may well apply to ecosystem and community conservation. We provide insights for leaders at any level in NGOs, government agencies, or research bodies into how to improve conservation results. 
Despite differing obstacles that conservation programs face, recognizable leaders have emerged at various levels within the conservation community. Few of these individuals received formal leadership training or development, although often their personal commitment and charisma has been an inspiration to colleagues. There are broader lessons to be learnt, however, concerning how leaders have influenced the outcomes of their programs. Consequently, an investigation of leadership approach, as distinct from personality, is long over-due to understand better how to lead conservation effectively (Deitz et al. 2004; Manolis et al. 2009).

\section{Leadership theory in mainstream literature and practice}

Even in mainstream management literature, there is no agreed definition of "leadership," (Kennedy 1994; Seddon 2003) although several categories of leadership model have emerged.

(1) From the 1900s, traditional "command-and-control" leaders utilized structures, laws, incentives, threats, contracts, and standards (Holling \& Meffe 1996; Macdonald 1998). Quasi-military leadership concepts extended the model in the 1940s (Kennedy 1994). Command-and-control focuses on efficiency of the organizational "machine"; managers make decisions, specialists are centralized into functional divisions, and workers complete ever-simplified tasks.

(2) Behavioural theories have since challenged the ideals of command and control, initially with McGregor's (1957) "Theory $\mathrm{Y}$ " for managing people using "more adequate assumptions of human nature and human motivation." "Situational leadership" (Hersey \& Blanchard 1969) introduced the idea that effective leaders adapt their style relative to the task and the competence of staff. Adair's (1979) "task-teamindividual" model added teamwork into this contextdependent philosophy.

(3) The 1970s saw the emergence of "transactionaltransformational" leadership (Burns, 1978), which combines leaders' reinforcement of workers' performance ("transactional" leadership behaviour) alongside new "transformational" behaviors that aim to engage people in the organization's purpose by enhancing motivation, understanding, and self-worth (Bass 1997). Proponents encourage clear vision, values, personal credibility, technical competence, conceptual skills, judgment, experimentation, and facilitating involvement (Peters 1987; Kouzes \& Posner 1987; Bennis 1999). Evidence suggests the best leaders are both transactional and transforma- tional (Bass 1997), although in the past 20 years, trends in literature and education have shifted to solely emphasize transformational behavior (Tourish 2008).

(4) Transformational leadership is now the dominant leadership paradigm (Kennedy 1994). Leaders are portrayed as changed masters and heroes (Slater 1999; Kanter 2003), encouraged to transform the habits, loyalties, and behaviors of their staff to develop a shared culture. However, people are perceived as the source of problems (Heifetz \& Laurie 1997) and other negative effects occur, stifling dialogue and effective problem solving and blinding leaders to viable alternatives (Seddon 2003; Tourish 2008); the coercion of people through behavioral tools and hierarchy is reminiscent of command-andcontrol's structures and rules.

(5) An alternative theory, originating in the 1920s (Shewhardt 1931) and developed in the 1940s by Deming (1982) is "systems thinking." A systems thinking leader aims to optimize links between management behavior, work rules, structure, decision making, skills, methods, and results (Senge 1990; Womack \& Jones 1996; Seddon 2003). The leader's role is one of "working on the system"; a fundamental change from the "working on people" approaches advocated by both command-and-control and transformational models (Seddon 2003; Reed 2006).

An important emerging theme in leadership is the move away from considering the leader as separate and "strategic," toward a role that is closer to operational activity (Hamel 2009; Mintzberg 2009). Parallel theories in organization development and human psychology identify how leadership processes contribute to the achievement of organizational purpose, and that leadership is linked to system characteristics and dynamics (Zaccaro $\delta$ Klimoski 2001).

In short, a leader's thinking and approach influences the focus, operation, structure, policy, goal setting, and decision making in their organization (Macdonald 1998; Seddon 2003). Unfortunately, many managers adopt leadership approaches that, although apparently plausible, have unhelpful impacts on the operation of their organization and the results that are achieved (Macdonald 1998; Seddon 2003).

For conservation leaders, understanding the link between leadership, organization structure, policy, goal setting, decision making, and achievement of results is important since previous analyses of ineffectiveness in species conservation programs identify shortfalls in all of these aspects (Clark et al. 1994; Clark 1997). Our evaluation of conservation leadership draws on management 
theory and our own review of effective and ineffective approaches to managing species conservation programs. We identify key features of good leadership and challenge unhelpful conservation leadership paradigms. Knowing the shortfalls and problems highlighted in welldocumented species conservation programs, we suggest a new leadership approach that leaders should consider and adapt to influence improvements in achievement of conservation results.

\section{Characteristics of species conservation programs}

Conservation organizations vary in mission, structure, decision making, technical capacity, and funding (Sutherland et al. 2009), yet certain common traits and challenges are evident in well-documented conservation cases. (1) Conservation organizations have an unusual focus; although they are often driven by a long-term vision, which can require decades to achieve (e.g., habitat or species restoration), activity must follow short-term cycles (e.g., one breeding cycle to the next) to suit the needs of species, landscapes, and communities while often complicated by time-bound funding horizons. (2) The work is a mix of scientific activities (e.g., population monitoring, genetics) alongside practical interventions (e.g., predator eradication, replanting habitat). Multi-disciplinary teams are common, often further complicated by a mix of experts and nonspecialist workers. Work also often involves difficult-to-access locations, remote work forces, or logistical complexities. (3) Conservation programs are by their nature open systems (Wallace 1994), which must interact with the environment over time. The outcomes of conservation work are, therefore, somewhat unpredictable (Holling 1978). Not all factors will be within a program's sphere of control (e.g., climate, war, pollution, politics), so leaders must be flexible to address changing needs and threats and to adapt working methods while maintaining scientific and professional rigor (Maris \& Béchet 2010). (4) Conservation needs are specific to most situations and species, so activities tend to adjust as knowledge and expertise develops within a specific context (e.g., population size, species needs, habitats, mitigation of threats). Consequently, approaches that assume particular organizational structures, sequences of methods, or rely on standards and protocols are of little use (Holling \& Meffe 1996; Clark 1997). (5) Conservation projects can frequently involve collaborations between western organizations (often fund-holding agencies keen to implement action) and host-country partners who may view proposed initiatives differently, yet who ultimately decide whether to permit implementation. The often asymmetrical nature of these cross-cultural, international relation- ships, while not unique to conservation, can be a source of challenges, frustrations, delays, and, on occasion, failure (Turvey 2008).

\section{Ten common problems in species conservation programs: symptoms of weak leadership}

Achievement in species conservation programs is typically hampered by problems of structure, policy, bureaucracy, hierarchies, political infighting, stalling, and slow decision making (Clark et al 1994). Numerous case studies suggest that these problems reinforce failure in otherwise well-resourced programs, with negative impacts on conservation (Walters 1992, 2006; Schaller 1993; Clark 1997; Snyder \& Snyder 2000; Powell 2008; Turvey 2008). Several recurring difficulties in species conservation programs can be traced to the observed style of leadership:

(1) Unachievable goals in terms of scope, time scale, or assumptions (Turvey 2008; Black \& Groombridge 2010).

(2) Excessive bureaucratic structures or functional divisions (Walters 1992; Wallace 1994).

(3) Not sharing information in a timely manner; a likely function of bureaucracy, apathy, or error (Clark 1997; Powell 2008).

(4) Poor decision making, slowed by hierarchy, risk aversion, or uninformed decision making, often complicated by limited availability of robust data (Backhouse et al. 1994; Powell 2008).

(5) Ideologically driven staff who do not commit to or agree with the culture of the program, for example, conflict over interventionist versus noninterventionist approaches (Snyder \& Snyder 2000).

(6) Methodological dissonance across the program, including different technical preferences in a team (Snyder \& Snyder 2000; Powell 2008.)

(7) Spending too much time on unsolvable issues outside (or not yet under) the direct influence of the program (Clark 1997; Powell 2008).

(8) Stifling innovation by adherence to procedure and protocol (Powell 2008; Turvey 2008).

(9) Failure to learn or seek advice, or conversely, inappropriately delegating decisions to outsiders (Clark 1997).

(10) Rigid people management and a failure to play to people's strengths within the team (Clark 1997; Turvey 2008).

This list of common problems typifies Seddon's (2003) observation of symptoms, which reflect leaders' 
Table 1 Comparison of leadership by command-and-control versus systems thinking across a range of management principles (adapted from Seddon 2003).

\begin{tabular}{lll}
\hline Principle & \multicolumn{1}{c}{ Command-and-control } & \multicolumn{1}{c}{ Systems thinking } \\
\hline Perspective for organizational design & Top-down hierarchy & Open system, outside-in \\
Design of work & Functional specialism & Understand needs and relevant flows of activity \\
Decision making & Separated from work & Integrated with work \\
Measurement & Output, targets, standards: related to budget or plan & Capability, statistical data: related to purpose \\
Attitude to biodiversity & Contractual: only do what is required (e.g., in recovery plans) & What matters? (e.g., to species, habitats) \\
Attitude to stakeholders & Contractual & Cooperative \\
Role of managers & Manage people and budgets & Act on the system \\
Ethos & Control & Learning \\
Approach to managing change & Reactive projects & On-going, integral (part of normal work) \\
Motivation of people & Extrinsic (reward and punishment) & Intrinsic (self-motivated)
\end{tabular}

deliberate or inadvertent adoption of an unhelpful "command-and-control" leadership philosophy (Table 1). Many observers note that the assumptions and behavioral consequences of command-and-control leadership are counter-productive and reduce organization effectiveness (Deming 1982; Macdonald 1998; Seddon 2003). Specifically in conservation, a command-andcontrol mentality can blind leaders to important issues through goal displacement-shifting focus away from purposeful, conservation-related objectives to follow instead organizational objectives, such as improving efficiency or implementing protocols (Wallace, 1994; Holling \& Meffe 1996; Snyder \& Snyder 2000; Reed 2006). Another difficulty is a functional mindset (i.e., separation of specialist work from routine work), which drives the development of ineffective bureaucracies, impedes communication, causes delays, and absorbs resources (Oakland $2001)$.

Many of these problems will be familiar to practicing conservation biologists; command-and-control remains a resilient default mindset (Seddon 2003), which conservation leaders appear prone to adopt (Holling $\delta$ Meffe 1996). A more effective leadership approach is needed.

\section{Ten positive traits: symptoms of leadership in successful species conservation programs}

We used an understanding of mainstream leadership theory to compare the characteristics of leadership in well-documented cases of conservation success and failure. This enabled identification of leadership approaches, which are associated either with helping or hindering conservation achievement. Our analysis included documented examples of poor performance, including the dusky seaside sparrow (Walters 1992), giant panda (Schaller 1993), black-footed ferret (Clark 1997), Yangtze River dolphin (Turvey 2008), and Po'ouli (Powell 2008), examples of success, including the Chatham Island black robin (Butler \& Merton 1992) and the peregrine falcon (Cade $\&$ Burnham 2003), and an example of turnaround from failure to success in the California condor (Snyder \& Snyder 2000). An analysis of these cases and other examples in literature (Clark et al. 1997) consistently identifies themes that commentators attribute to the problems or improvements observed in each instance. Our analysis of these themes identifies congruence with specific leadership theory, which is validated by our observations of leadership in many other programs. This analysis suggests that the best performing species conservation programs are those where leaders exhibit specific behaviors and expectations in terms of the following:

(1) Setting short-term achievable goals that account for, and adapt to, constraints in the system of work, including breeding cycles, seasons, and climate (Backhouse et al. 1994) yet remain focused on a broader long-term vision.

(2) Collecting data on basic natural history in early phases of the project, to develop a sound understanding of the biological system (Caughley 1994).

(3) Understanding the ecology and population history (including the period before decline) with changes and cycles properly interpreted (Caughley \& Gunn 1996).

(4) Installing high-performance teams of experts, using effective methods, high-work standards, and a willingness to make decisions, share, learn, and improve (Snyder \& Snyder 2000).

(5) Learning from experimentation and failures in order to improve, rather than accepting defeat and abandonment of the program (Kleiman et al. 2000). 
(6) Learning from other programs and using outside expertise if needed (Snyder \& Snyder 2000).

(7) Projecting a long-term view and an appreciation that species restoration programs usually take decades rather than years to achieve (Deitz et al. 2004).

(8) Engaging in both program details and wider interproject management issues (Clark 1997).

(9) Encouraging institutional memory: long-term involvement of key players and sharing of learning (Holling \& Meffe 1996).

(10) Using and managing creative friction between partners (Deitz et al. 2004), for example, between large NGOs and small NGOs, or between NGOs and government departments.

The leadership approaches adopted by successful programs reflect a task-oriented organizational culture relevant to the conservation sector (Clark 1997; Westrum 1994) and resonate with the philosophies of systems thinking (Deming 1982; Womack \& Jones 1996; Oakland 2001; Seddon 2003). The systems thinking perspective takes an "outside-in" view of the work, where the focus of people's work effort is on the organization's purpose. Furthermore, while leaders in the best performing species conservation programs appear to use systems thinking (either deliberately or intuitively), the converse is also observed; in failing programs, systems thinking is markedly absent whereas the characteristics of command-and-control leadership remain prolific.

The contrast between systems thinking and commandand-control is set out in Table 1 . The systems thinking approach requires leaders to focus on results relating to program purpose and the effectiveness of work, not other institutional, personal, or political objectives. Leaders should examine how performance is measured, how people are motivated, and how work is designed and improved (Seddon 2003). Systems thinking allows leaders to consider and respond appropriately to uncertainty and the combinations of persistence, change, and unpredictability that is associated with natural systems (Holling 1978; Wallace 1994).

Leading with a systems perspective focuses people on continuous learning to improve the capability of a program. Even where there are little, if any, robust data to support decision making, proactive methods can address these limitations, such as VanderWerf et al's (2006), decision-making process applied by a new team in late attempts to recover the Po'ouli. Based on our observations and analyses, we suggest that systems thinking provides a better approach for conservation leaders. The following two species recovery examples demonstrate the practical relevance of systems thinking to conservation. The first case describes the consequences when characteristics of systems thinking are absent, and the second case illustrates the positive impacts observed when those characteristics are present.

\section{Battling the inertia of command-and-control: the Po'ouli as a case study}

The Po'ouli (Melamprosops phaeosoma) is a species of Hawaiian forest honeycreeper, endemic to Maui and first discovered in 1973, when it was considered a rare species with limited range (VanderWerf et al. 2006). Figure 1 illustrates how changes in estimates of population size suggested a decline in the species after its initial discovery from densities of 76 per square kilometer in 1975 to 8 per square kilometer by 1985 (Groombridge et al. 2004), although actual observations of the bird were always low (Baker 2001), at least partly influenced by the cryptic nature of the species and the difficulty of gaining access to and surveying in its habitat.

In the first 20 years of this species' formal consideration under the U.S. Endangered Species Act, conservation work was conducted within bureaucratic multi-agency structures of the United States Fish and Wildlife Service and the State of Hawaii Department of Land and Natural Resources (Powell 2008). Funding relating to the recovery of this species and its habitat was generated through the Endangered Species Act and invested in habitat protection and improvement, despite no more than 15 individual birds ever having been observed in the wild. Several population studies on the Po'ouli were completed, but there was no concerted effort to gain an understanding of the species' ecology and population biology, nor a detailed diagnosis of factors driving its decline (i.e., the overall system, in which the recovery program was operating).

During the first two decades following the discovery of the Po'ouli, leadership attitudes reflected caution and uncertainty regarding how to proceed, inevitably resulting in little action. Management options for the dwindling number of known birds were not considered until too late and techniques to conserve this species were never fully developed. Although translocation of some of the remaining three known individuals (thought to be two females and one male) was proposed in 1999, in the hope of creating a breeding pair and stimulating breeding activity (DLNR \& USFWS 1999), this plan was not implemented due to bureaucratic delays until 2002 when a new field team made the first attempts to develop and then conduct the translocation. Although these activities increased knowledge of Po'ouli feeding ecology 


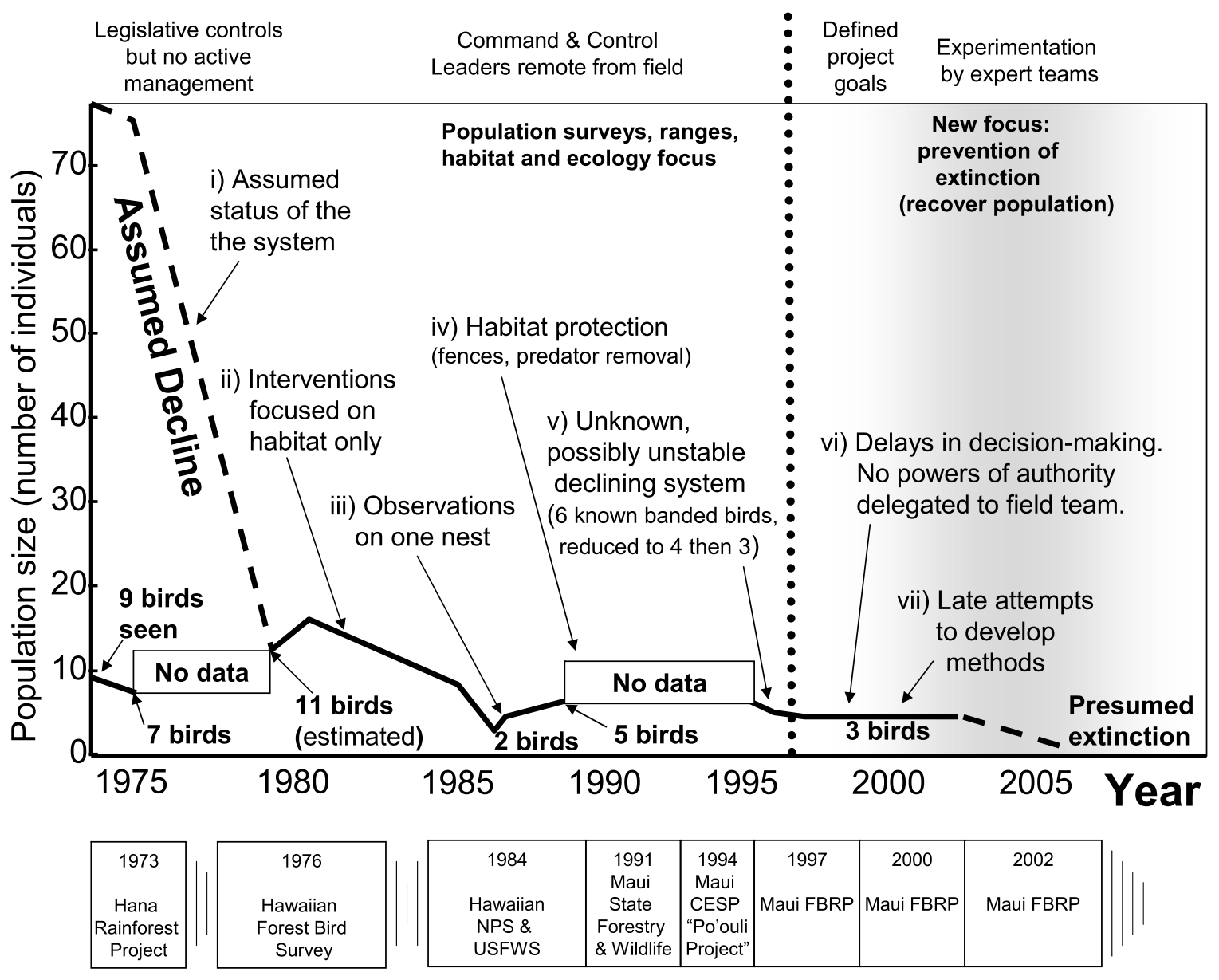

Figure 1 Po'ouli: population status, program management, and patterns of leadership. The population curve is shown by a thick black line indicating total known individuals, with estimated population numbers indicated by a dashed black line. The observed change in leadership approach is indi- cated by the vertical dotted line. Boxes at the base of the figure indicate changes of leader in the management teams during the program (DLNR \& USFWS 1999; Baker 2001; Groombridge et al. 2004; VanderWerf et al. 2006; Powell 2008;). and hinted at potential for captive husbandry, this intervention failed, possibly occurring too late in terms of the reproductive age of those individuals (Groombridge et al. 2004). One of the three birds, a male, was captured in 2004 but died later that year before a mate could be located (VanderWerf et al. 2006). No Po'ouli has been observed since, and despite millions of dollars invested the species is presumed extinct.

Figure 1 describes how changes in the leadership approach were evident in this program, but came too late to affect the species. Arguably, the amount of learning and knowledge gained in the last few years far exceeded that gained from the previous quarter of a century. The lack of a long-term vision and an overcautious approach resulted in years with little action while the Po'ouli population steadily declined (Powell 2008). An earlier oppor- tunity to break the constraints of command-and-control with better leadership might have stimulated positive interventions sooner.

\section{Positive impacts of changing the leadership approach: the California condor}

The California condor (Gymnogyps californianus) population was in decline for decades following the first detailed study in the 1930s and 1940s (Koford 1953). A largely "nonintervention" strategy, which reflected the conservation perspectives of the time, was used until the species' formal listing under the U.S. Endangered Species Act. There then followed an intensive debate between 
United States Fish and Wildlife Service bureaucrats and scientists, and wildlife managers concerning the causes of the population decline and whether or not to intervene. Many observers were skeptical that intensive management would work which led to a strong "hands-off" lobby by many environmentalists (Phillips $\&$ Nash 1981). During this period, the factors contributing to the condor's decline were poorly understood or misdiagnosed, being variously assigned to excessive shooting and poisoning (Miller et al. 1965), food scarcity (Wilbur 1978), and dichlorodiphenyldichloroethylene (DDE) contamination, which caused breeding failure (Kiff et al. 1979). These differences in opinion caused misdirection of the program and a lack of coherent vision for what could be achieved.

Not until the intensive studies of the 1980s and 1990s did the true cause of decline become clear (lead poisoning caused by ingestion of lead shot from abandoned deer carcasses) for the project to develop a clear vision and strong direction (Snyder \& Snyder 2000). Here, in a highprofile project, it took half a century to diagnose the primary cause of the species' decline. By then however, the population had declined so low that conservation intervention had been left until it was almost too late. Nevertheless, with a convincing diagnosis and a vision of how to proceed, some of the skepticism surrounding the management practices receded.

The recovery was a team effort led in the field by Noel Snyder who was largely responsible for focusing the research (Snyder and Snyder 2000). Despite mistakes and setbacks in the early 1980s, leaders persisted and reinvigorated the program by (1) adopting a focus on the California condor's immediate crisis (reproduction and population growth), (2) understanding the species and its needs, and (3) establishing high-performance teams able to experiment and develop effective conservation methods. Leaders instigated specific new practices including the first full censuses of wild birds, development of trapping techniques, blood sampling, radio-telemetry, dietary analysis, nest management, captive breeding, and release (Snyder and Snyder 2000). In 1987, with remaining wild birds still threatened by lead poisoning, all were taken into captivity for captive breeding with the aim of releasing the progeny. Captive management initially came under the San Diego and Los Angeles Zoos with overall supervision by Mike Wallace.

Dogged determination to continue to develop this process has seen partial and continuing recovery of the species and the population today now exceeds the level of 100 years ago. Figure 2 illustrates how a change in leadership focus matched a step change in the population status of this species. New initiatives are being developed with farmers, landowners, and hunters and new habitats are being used for reintroduction. A turnaround in leadership thinking has provided a potentially sustainable future for the largest flying bird in North America.

\section{The key qualities in an effective conservation leader}

It is not straightforward for a leader to know how to adapt their approach to improve the effectiveness of their program. Our summary provides a first comprehensive synthesis of the required perspectives, approaches, and practices, which we believe will assist conservation leaders. Our review has included conservation cases previously discussed, our direct observations of effective approaches by conservation leaders, reference to leadership behaviors congruent with mainstream management theory and practice, and identification of actions to reverse negative impacts frequently observed in species conservation programs. Such a synthesis is validated by our first-hand experiences in leadership and program participation. Table 2 presents a list of recommended characteristics, qualities, and action that a systems thinking leader should apply in a conservation setting. In summary, we advocate the following qualities as those most important for conservation leaders:

(1) Ability to share a clear, long-term vision. A leader needs to establish a stable, shared long-term vision to guide the work of the program. The vision should be simple to understand and easily defined through clear, short-term achievable goals (Coppin \& Barratt 2002), which leaders need to communicate clearly by words and action. The time frame and method might be ill defined, but goals set on a relevant short-term cycle provide clarity. Goals should be set to ensure long-term conservation, but most importantly, action must be initiated early, with continuous monitoring to avoid irreversible decline (Clark et al. 1994).

(2) Orientation toward "hands-on" management. Conservation leaders should possess good knowledge and experience, understand teamwork, and be able to work with others. A leader should know how to ask relevant questions about work, and encourage staff to make improvements (Hamel 2009), focusing on process improvement rather than micro-management of people. Competent teams should be given space and authority to carry out their work (Clark et al. 1994). A leader should know the strengths and weaknesses of staff and how to manage and develop them to best effect (Black \& Groombridge 2010). Leaders should encourage celebration of success and ensure constructive lessons are learnt from failures (Coppin \& Barratt 2002). 


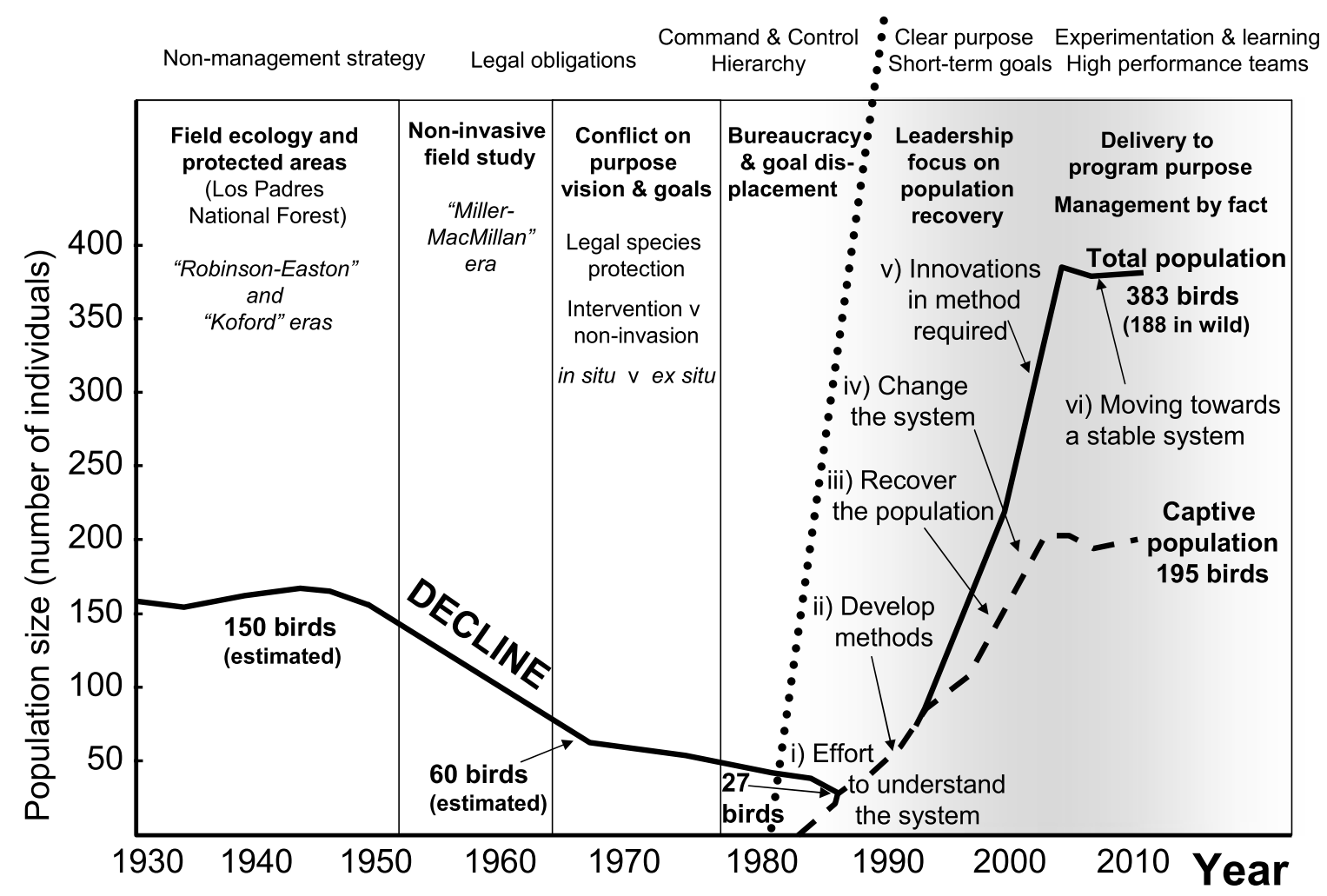

Figure 2 California condor: population status, program management, and patterns of leadership. The population curve is shown by a thick black line indicating total individuals (including estimates where indicated), with the captive population indicated by a dashed black line. The various man- agement team phases are indicated by vertical lines. The observed change in leadership approach is indicated by the vertical dotted line. (Koford 1953; Miller et al. 1965; Wilbur 1978; Phillips \& Nash 1981; Snyder \& Snyder 2000; USFWS 2010).

mistakes are inevitable, but an effective leader will be able to recognize the difference between those caused by neglect, those caused by a lack of training, experience or resources, and others caused by a poor understanding of the system. A dialogue of constructive criticism and informed challenge will encourage learning and improvement (Clark \& Reading 1994; Tourish 2008).

\section{Conclusions}

Rather than simply reviewing current paradigms of leadership found in management literature, we have instead purposefully distilled aspects of leadership which (1) resonate with the needs of conservation leaders, (2) broadly match those approaches frequently encountered in successful conservation programs, and (3) are strongly rooted in established management theory and well-informed contemporary management practice.

Conservation practitioners want to be involved in activities based on timely decision making and scientific knowledge. Effective conservation leadership means 
Table 2 The qualities and abilities of an effective conservation leader.

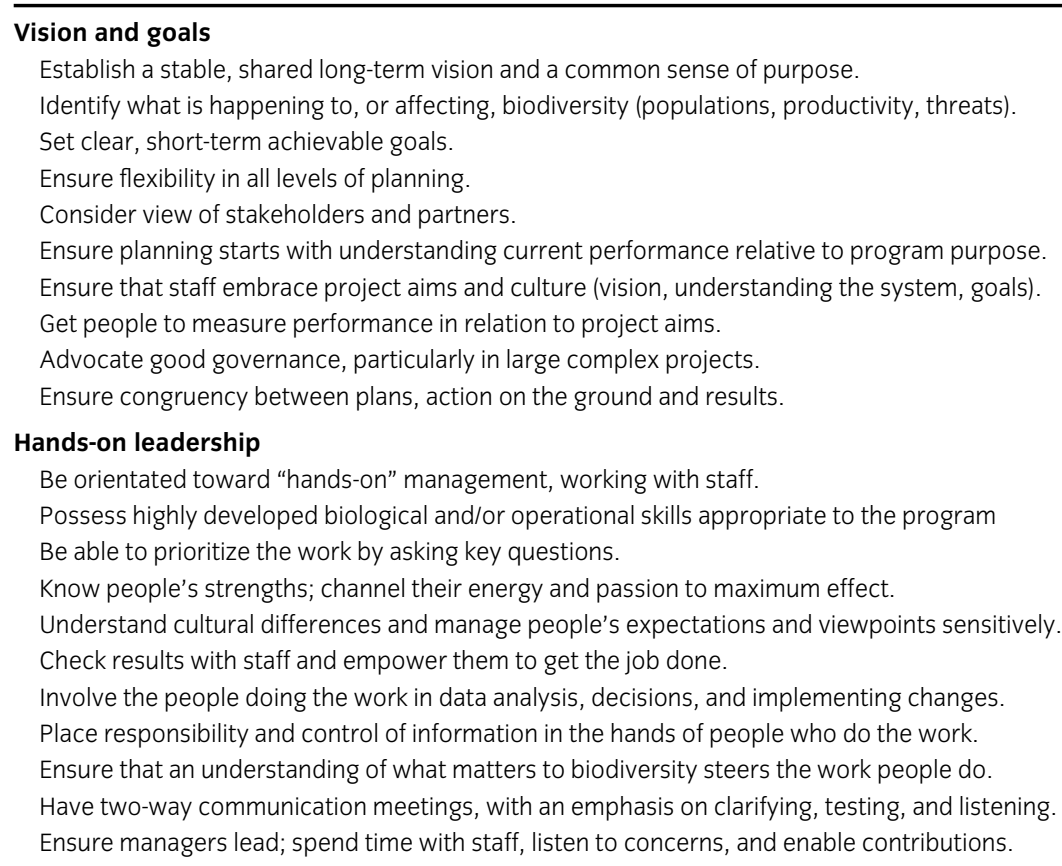

\section{Consider both project details and the big picture}

Focus both internally and externally, understanding intra- and inter-organizational dynamics. Know projects' sphere of influence-identify the solvable problems.

Establish budgets and a clear fund-raising strategy.

Examine financial and nonfinancial measures; which predict and cause conservation results?

Base information, technology, and resource needs on how they help people's core work.

Create an attitude of cooperation with project partners, sharing information to improve work.

Anticipate unexpected outcomes.

Be prepared to seek specialist advice from external sources.

Integrate management flexibility alongside professional/scientific rigor.

Determine whether data on staff, communities, or society would be useful for the program.

\section{Improvement and Learning}

Give people the opportunity to ask for training and provide it on a just-in-time basis.

Be receptive to (and seek out) alternative solutions.

Enable staff to challenge, share, and learn from mistakes, without fear.

Expect-and support staff to strive for-high standards.

Expect the project (and its needs) to evolve through time.

Understand risk factors and make suitable contingencies.

Appraise the system rather than people; manage morale, celebrate success, learn from failures.

Make improvements based on biodiversity needs and process performance, not arbitrary targets.

Recognize difference between neglect and lack of capability (training, experience, or resources).

Allow people doing the work, the freedom to experiment with methods to improve performance.

driving solutions to problems with continuous improvement on the ground, especially when dealing with threatened species. Leaders must capitalize on the qualities of their personnel to ensure these processes happen. Personal charisma is not the over-riding quality, although a preparedness to challenge assumptions, innovate, and make things happen is important (Westrum 1994). Successful conservation leaders need to be straightforward with people, think about the species they are working with, engage people's knowledge and focus their program on purposeful work. We argue that the successful leaders in species conservation tend to adopt a "systems thinking" approach. Our intention has been to inform and encourage conservation leaders to adopt this better way of leadership as a basis for successful conservation work, which can deliver improved and lasting results. 


\section{References}

Adair, J. (1979) Action-centred leadership. Gower, Aldershot, UK.

Backhouse, G.N., Clark T.W., Reading, R.P. (1994) The Australian eastern barred bandicoot recovery program: evaluation and reorganization. Pages 251-271 in T.W. Clark, R.P. Reading, A.L. Clarke, editors. Endangered Species Recovery: finding the lessons, improving the process. Island Press, Washington, D.C.

Baker, P.E. (2001) Status and distribution of the Po'ouli in the Hanawi Natural Area Reserve between December 1995 and June 1997. Stud Avian Biol 22, 144-150.

Balmford, A., Cowling R.M. (2006) Fusion or failure? The future of conservation biology. Conserv Biol 20, 691-695.

Bass, B.M. (1997) Does the transactional-transformational leadership paradigm transcend organizational and national boundaries? Am Psychol 52, 130-139.

Bennis, W. (1999) The leadership advantage. Leader to Leader 12, 18-23.

Black, S.A., Groombridge J.J. (2010) Use of a business excellence model to improve conservation programs. Cons Biol 24, 1448-1458. doi: 10.1111/j.1523-1739. 2010.01562 .

Butler, D., Merton D. (1992) The Black Robin. Oxford University Press, Oxford, UK.

Burns, J.M. (1978) Leadership. Harper and Row, New York, NY.

Cade, T., Burnham W. (2003) Return of the Peregrine: a North American saga of tenacity and teamwork. The Peregrine Fund, Idaho.

Caughley, G. (1994) Directions in conservation biology. J Anim Ecol 63, 215-244.

Caughley, G., Gunn A. (1996) Conservation Biology in Theory and Practice. Blackwell Science, Cambridge, MA.

Clark, T.W., Reading R.P. (1994) A professional perspective: improving problem solving, communication and effectiveness. Pages 351-369 in T.W. Clark, R.P. Reading, A.L Clarke, editors. Endangered species recovery: finding the lessons, improving the process. Island Press, Washington, D.C.

Clark, T.W., Reading R.P., Clarke A.L. (1994) Synthesis. Pages 417-431 in T.W. Clark, R.P. Reading, A.L. Clarke, editors. Endangered species recovery: finding the lessons, improving the process. Island Press, Washington, D.C.

Clark, T.W. (1997) Averting extinction: reconstructing endangered species recovery. Yale University Press, New Haven, CT.

Coppin, A., Barratt J. (2002) Timeless Management. Palgrave MacMillan, New York.

Deitz, J.M., Aviram R., Bickford S. et al. (2004) Defining leadership in conservation. Conserv Biol 18, 274278.

Deming, W.E. (1982) Out of the Crisis. Massachusetts Institute of Technology Center for Advanced Engineering Study, Cambridge, MA.

DLNR (Department of Land and Natural Resources) and
USFWS (U.S. Fish and Wildlife Service). (1999) Environmental assessment for proposed management actions to save the Po'ouli. DLNR and USFWS, Maui, Hawaii.

Groombridge, J.J., Massey J.G., Bruch J.C. et al. (2004) An attempt to recover the Po'ouli by translocation and an appraisal of recovery strategy for bird species of extreme rarity. Biol Conserv 118, 365-375.

Hamel, G. (2009) Moonshots for management. Harvard Bus Rev 87, 91-98.

Heifetz, R.A., Laurie D.L. (1997) The work of leadership. Harvard Bus Rev 75, 124-134.

Hersey, P., Blanchard K.H. (1969) Life cycle theory of leadership. Training Dev 23, 26-34.

Holling, C.S. (1978) Adaptive Environmental Assessment and Management. John Wiley \& Sons, Chichester, UK.

Holling, C.S., Meffe G.K. (1996) Command and control and the pathology of natural resource management. Conserv Biol 10, 328-337.

Kanter, R.M. (2003) Leadership and the psychology of turnarounds. Harvard Bus Rev 81, 58-67.

Kennedy, C. (1994) Managing with the gurus. Random House, London.

Kim, C.S., Spahlinger D.A., Kin J.M., Billi J.E. (2006) Lean health care: what can hospitals learn from a world-class automaker? J Hosp Med 1, 191-199.

Kiff, L., Peakall D.B., Wilbur S.R. (1979) Recent changes in California condor eggshells. Condor 81, 166-172.

Kleiman, D.G., Reading R.P., Miller B.J. et al. (2000) Improving the evaluation of conservation programs. Conserv Biol 14, 356-365.

Koford, C.B. (1953) The California condor. National Audubon Society Research Report No. 4, 1-154.

Kouzes, J.M., Posner B.Z. (1987) The leadership challenge: how to get extraordinary things done in organizations. Jossey-Bass, San Francisco, CA.

Macdonald, J. (1998) Calling a halt to mindless change. American Management Association International, New York.

Manolis, J.C., Chan K.M., Finkelstein M.E. et al. (2009) Leadership: a new frontier in conservation science. Conserv Biol 23, 879-886.

Maris, V. Béchet A. (2010) From adaptive management to adjustive management: a pragmatic account of biodiversity values. Conserv Biol 24, 966-973. doi:10.1111/j.15231739.2009 .01437$.

McGregor, D.M. (1957) The human side of enterprise. Manag Rev 46, 22-28.

Miller, A.H., McMillan I., McMillan E. (1965) The current status and welfare of the California condor. National Audubon Research Report No. 6, 1-61.

Mintzberg, H. (2009) Managing. Berrett-Koehler, San Francisco, CA.

Oakland, J.S. (2001) Total organizational excellence; achieving world class performance. Butterworth-Heinemann, Oxford, UK. 
Peters, T. (1987) Thriving on Chaos. Alfred A. Knopf, New York, NY.

Phillips, D., Nash H. (1981) The condor question: captive or forever free? Friends of the Earth, San Francisco, CA.

Powell, A. (2008) The race to save the world's rarest bird: the discovery and death of the Po'ouli. Stackpole Books, Mechanicsburg, PA.

Reed, G.E. (2006) Leadership and systems thinking. Defense ATOL 35, 10-14.

Schaller, G. (1993) The last panda. Chicago University Press, Chicago, IL.

Seddon, J. (2003) Freedom from command and control. Vanguard Press, Buckingham, UK.

Senge, P. (1990) The fifth discipline. Doubleday, New York, NY.

Shewhardt, W. (1931) Economic control of quality of manufactured product. Van Nostrand Company, New York.

Slater, R. (1999) Jack Welch and the GE Way: management insights and leadership secrets of the legendary CEO. McGraw-Hill, New York, NY.

Snyder, N., Snyder H. (2000) The California condor: a saga of natural history and conservation. Academic Press, London.

Sutherland, W.J., Adams W.M., Aronson R.B. et al.(2009) One hundred questions of importance to the conservation of global biological diversity. Conserv Biol 23, 557-567.

Tourish, D. (2008) Challenging the transformational agenda: leadership theory in transition? Manage Commun Q 21, 522-528.

Turvey, S. (2008) Witness to extinction: how we failed to save the Yangtze river dolphin. Oxford University Press, Oxford, UK.

USFWS (US Fish and Wildlife Service). (2010) California condor recovery program population size and distribution.
Available from: http://www.fws.gov/hoppermountain/ CACORecoveryProgram/ CurrentStatus.html Accessed October 2010.

VanderWerf, E.A., Groombridge J.J., Fretz J.S., Swinnerton K.J. (2006) Decision analysis to guide recovery of the po'ouli, a critically endangered Hawaiian honeycreeper. Biol Conserv 129, 383-392.

Wallace, R.L. (1994) The Florida Manatee recovery program: uncertain information, uncertain policy. Pages 131-156 in T.W. Clark, R.P. Reading, A.L. Clarke, editors. Endangered species recovery: finding the lessons, improving the process Island Press, Washington, D.C.

Walters, M.J. (1992) A shadow and a song: the struggle to save an endangered species. Green Publishing Company, Post Mills, Vermont.

Walters, M.J. (2006) Seeking the sacred raven: politics and extinction on a Hawaiian Island, Island Press, Washington, D.C.

Westrum, R. (1994) An organizational perspective: designing recovery teams from the inside out. Pages 327-350 in Clark, T.W., Reading R.P., Clarke A.L, editor. Endangered species recovery: finding the lessons, improving the process Island Press, Washington, D.C.

Wilbur, S.R. (1978) The California condor, 1966-76: a look at its past and future. U.S. Fish $\theta$ Wildlife Service North American Fauna 72, 1-136.

Womack, J.P., Jones D.T. (1996) Lean thinking: banish waste and create wealth in your corporation. Simon \& Schuster, London, UK.

Zaccaro, S.J., Klimoski R.J. (2001) The nature of organizational leadership: understanding the performance imperatives confronting today's leaders. Jossey-Bass, San Francisco, CA. 